\title{
Toward implementing a fully automated truck guidance system at a seaport: identifying the roles, costs and benefits of logistics stakeholders
}

\author{
Valentin Carlan ${ }^{1 *}$ D, Dries Naudts ${ }^{2}$, Pieter Audenaert ${ }^{2}$, Bart Lannoo ${ }^{2}$ and Thierry Vanelslander ${ }^{1}$
}

\author{
*Correspondence: valentin.carlan@ \\ uantwerpen.be \\ 'Department Transport \& Regional \\ Economics, University of Antwerp, \\ Prinsstraat 13, 2000 Antwerpen, \\ Belgium \\ Full list of author information is \\ available at the end of the article
}

\begin{abstract}
The seaport-hinterland access infrastructures become more saturated leading to extra unpredictable costs for logistics operators. To keep their services competitive, infrastructure managers (such as port authorities) seek new approaches in managing and delivering information to their users. Starting from existing technological advancements and exploring the declared opportunities enabled by (near) future ones, a range of solutions (e.g. real-time information platforms, dynamic information boards or digital on-request notification solutions) can be pursued. This research investigates how an advanced truck guidance system (TGS) leverages on technology and leads to more efficient resource (infrastructure, equipment and labour) usage. The current paper merges two perspectives. The first conducts interviews with representatives of different logistics stakeholders to highlight their data needs. The second perspective is given by a review of information communication technology (ICT) innovative trends. These two perspectives provide an up-to-date overview of both needs (demand) and opportunities (supply) that challenge logistics stakeholders. This study proposes a TGS architecture that merges the two perspectives and identifies a stepwise approach to implement it. Therefore, the roles, costs and benefits brought to the logistics stakeholders are highlighted for each step. The key findings of this study show that road transport operators would benefit from operational savings and increased performance, while the other supply chain stakeholders can benefit from setting up a more reliable planning, better managing their infrastructure and developing added-value services for clients. To enable these benefits, the port administration could take the facilitator role and cover the TGS's development costs.
\end{abstract}

Keywords: Truck guidance system, Seaport, Users benefits, Implementation strategies

\section{Introduction}

North-Western European ports' hinterland connections are mostly ensured by road transport. Ports located in North-Western Europe have a relatively (as compared to other European ports) low modal share when it comes to road transport ensuring their hinterland connections. In 2017, the modal split of freight carried by road was 59\% for the port of Hamburg, 53\% for the port of Rotterdam, 52\% for the port of Antwerp, and

(c) The Author(s). 2019 Open Access This article is distributed under the terms of the Creative Commons Attribution 4.0 International License (http://creativecommons.org/licenses/by/4.0/), which permits unrestricted use, distribution, and reproduction in any medium, provided you give appropriate credit to the original author(s) and the source, provide a link to the Creative Commons license, and indicate if changes were made. 
$50 \%$ for the port of Bremen. The port of Antwerp, the second largest port in NorthWest Europe, has already one of the lowest modal split for freight carried to and from the hinterland by road. Moreover, road transport operators deal with congestion and delays as the road transport network becomes saturated. In this context, road hauliers operate in a highly competitive ecosystem, where sub-optimal decisions with regard to infrastructure use are made. These elements have impact not only on the activity of the road transport operators themselves, but also on the efficiency of the related maritime supply chain (MarSC) stakeholders such as maritime carriers, terminal operators, shippers and consignees, affecting their competitiveness. Therefore, port authorities seek for ways to facilitate the use of new ICT advancements for better services that involve data collection (e.g. real-time traffic information, parking availability, gate waiting times etc.), data storage and processing (e.g. servers, cloud technology, etc.), and data usage (e.g. digital road signs, online platforms, users' own interfaces, data push to vehicle onboard units or other mobile devices).

Despite the high potential represented by technology, the presence of a high number of ICT solutions on the market creates heterogeneous working practices (D'Este et al. 2012). Firms develop own working practices using own set of IT tools. Heterogeneity is also a characteristic of the road transport market. Moreover, the road transport market is segmented and consists of a high amount of players with low physical capital (low number of transport assets). This situation is presented in Fig. 1 from the perspective of Belgium. This general trend with regard to the size and the amount of assets owned by road transport companies in Belgium is seen as well throughout countries of NorthWestern Europe. In Belgium, on a total of approximately 8700 road transport companies, around $3200(37 \%)$ are companies with one vehicle. This landscape puts a lot of pressure on information technology (IT) developers to consider solutions that are both suitable for large operators with relatively higher financial capabilities, but at the same time also for small operators that form the greater market share and have a low willingness to pay. While relatively large companies have invested in state-of-the-art solutions to manage their fleet of vehicles and drivers, small operators are still using traditional solutions (e.g. retrieval of information by phone on an individual basis from the

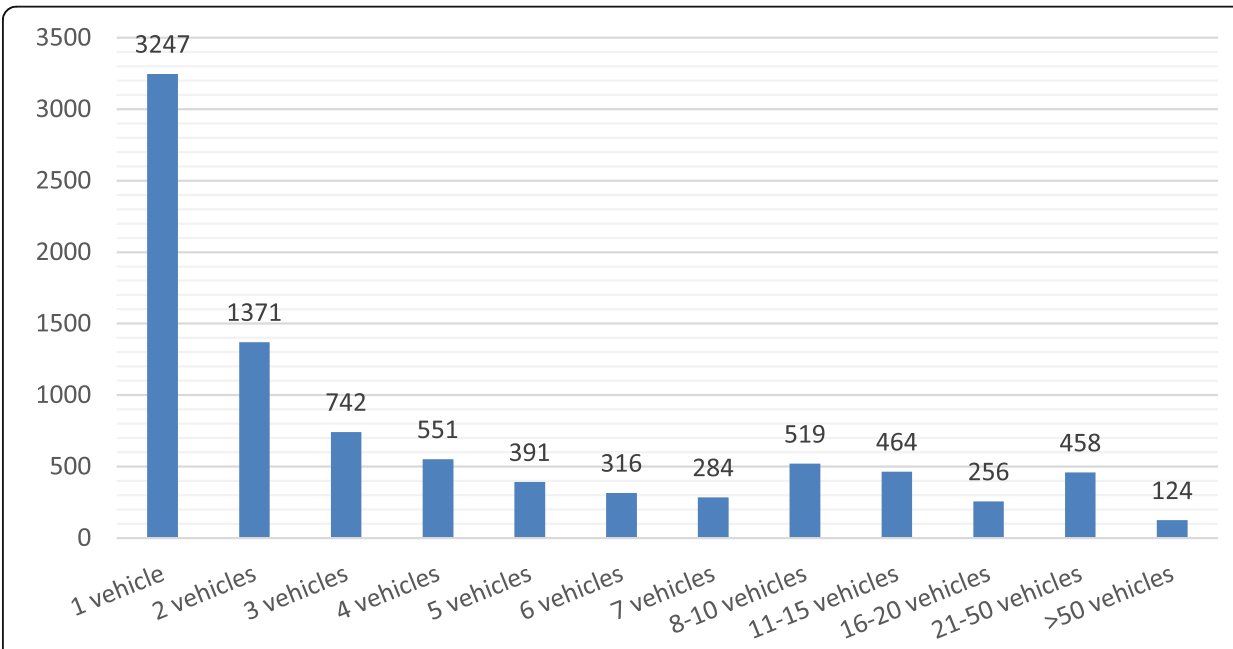

Fig. 1 Overview of Belgian trucking companies' fleet size [source: FOD Mobiliteit 2017] 
terminal operators) and base themselves on other public information scattered across different sources to deal with their operational daily issues.

To overcome these problems, it is worthwhile to investigate how an advanced TGS leverages contemporary technologies to lead to more efficient resource usage, such as roads, parking lots, terminals, containers, etc. Available technologies should be incorporated in an advanced TGS adapted to port users' needs. Also, a clear roadmap and action plan is needed on how such a system is developed and brought to the different stakeholders that are involved in the transport and processing of containers from and to the seaport. This action plan should indicate which steps and priorities are essential to implement such a comprehensive TGS, showing the incentives for each stakeholder. The intermediary steps in achieving a state of the art Truck Guidance System (TGS) and their implementation strategy make the focus of the present research.

To achieve the goals of this research, the port of Antwerp was taken as case study, where the port authority is confronted with a high demand for supporting the implementation of a TGS.

By conducting in-depth desk research and interviews with stakeholders, this research aims at the following three objectives. Firstly, it puts forward the functionalities and the architecture of a TGS to be developed at a seaport. By doing so, this research points out the steps needed to be undertaken in achieving a fully automated TGS. Secondly, the costs and benefits of the proposed TGS are pointed out. Third, the paper aims at identifying the roles of both technology developers and MarSC stakeholders in achieving an enhanced TGS. Therefore, a final strategy analysis is conducted, considering the possible roles the port administration can play. This analysis points out the MarSC stakeholders' and ICT solutions developers' interest, specialization, need for further specialization or no immediate interest in a TGS.

The structure of the paper is as follows. Section 2 gives a literature review of both port-related ICT tools in general, and on TGS' in particular to frame to topic of research. Section 3 summarises the research methods further used. Section 4 provides a collection of insights with regard to port stakeholders communication needs, roles and ICT truck solutions in/around ports. Section 5 presents the main findings of this research with regard to the steps and the functionalities of a TGS. Within this section, a discussion on three scenarios analysing the roles of the involved stakeholders is elaborated. The conclusions and recommendations for future research are in Section 6.

\section{Literature review}

This section discusses firstly the nature of problems encountered in road haulage and contributes at determining the further research approach. Therefore, it presents the issues related to information exchange and role of ICT tools in port and hinterland logistics. In addition, it shows the main findings of a literature review with regard to a truck guidance system.

\section{Information issues in port-related trucking}

The problems faced by the trucking industry and the other stakeholders involved in container transport from and to all major seaports are multiple. Yet, with regard to 
information access or information communication, the contemporary focus falls on the following items:

- Lack of transparency and predictability of the traffic situation (especially for trucks) (Zhao and Goodchild 2010; Hill and Böse 2017):

- Arrival time of trucks is not always known

- Difficulty to take the different traffic situations into account in the planning phase

- Need for cross-process communication and coordination through the logistics chain to optimize operations (Cao et al. 2010; Rushton et al. 2014):

- Lack of communication and data sharing between stakeholders

- Lack of centralized information which is needed for efficient truck planning

- High delay and handling time at the terminal

- Inefficient gate operations

- Inefficient retrieval of free parking spaces

\section{Transport- and port-related ICT tools}

The transport sector has started to develop information communication technology (ICT) solutions over 30 years ago and is expected to continue even more after 2020 (Mohr et al. 2013). The literature review carried out by Harris et al. (2015) shows that the terminology used for ICT transport solutions evolved from telematics provided for road transport to contemporary smart/intelligent solutions that make use of technologies such as cloud storage, Internet of Things (IoT), Big Data analysis, Cryptocurrencies or Blockchain. So, the continuous introduction of new technological achievements in daily operations in transport is acknowledged, yet the full costs and benefits that they generate are not shown in an exhaustive framework.

Given the relevance of port and hinterland transportation in the global supply chains, available literature encourages increasing operations visibility of port-related stakeholders (Song and Panayides 2008; Woo et al. 2013). A key aspect to increase transparency in (maritime) supply chains (SC) operations is connectivity or information sharing through electronic linkages among supply chain partners. Academia shows that increased information sharing between the port and supply chain actors contributes to reducing order cycle times, cutting inventories and achieving more flexible systems (Woo et al. 2013). In fact, it helps them to better accommodate the highly-fluctuating demand for transportation and remain active in a competitive, low-margin industry (Panayides and Song 2013). Haralambides (2017) points out that improvements with regard to information systems, among others, can be seen as a first step towards port reform without pursuing other fundamental changes (such as organizational or policy shifts). These improvements have effects on existing capacity usage as they enable new asset management opportunities to be applied in ports' hinterland operations, also as remarked by Wiegmans et al. (2018).

All seaports face continuously new challenges in meeting transport growth rates while the capacity of infrastructure stagnates (Castelein et al. 2019). Loads such as containers, break bulk or liquid bulk cargo are always relying on road transport as a part of their SC. In this context, road freight transport is an important player in the logistics 
chain that cannot be completely substituted for. Tools that lean on existing technology are needed in developing tools that optimize this part of the logistics chain. The following sub-section gives an overview of research initiatives exploring the functionalities of a truck guiding system at seaports.

\section{TGS tools}

Previous research has studied the implementation of truck guidance (appointment) systems at ports' terminals. Zhang et al. (2013) present research on the topic of TGS and a model that describes the queuing process of trucks at a terminal, using Genetic Algorithm (GA) and Point wise Stationary Fluid Flow Approximation (PSFFA). Their results indicate that the proposed PSFFA method can estimate the queue length accurately and the model can decrease the truck turnaround time efficiently. Moreover, the research of Yanhong and Xiaofa (2013) provides early evidence on the effect that GPS data mining has on freight truck operations. They show that by using GPS data, freight modelling can offer reliable results and reduce planning errors.

The benefits of a truck appointment system are studied from the perspective of the inland transport modes by Zehendner and Feillet (2014). They provide a tool to use the truck appointment system to increase not only the service quality of trucks, but also of trains, barges and vessels. Their model is based on a network flow representation of the terminal and aims to minimize its overall delays. They provide quantitative results and proves that fewer delays occur at a terminal with a truck appointment system than at a terminal without. Phan and Kim (2016) develop a mathematical model by which trucking companies and terminals can collaboratively determine truck schedules and appointments for truck arrivals. Several conditions are discussed and the computational time necessary for each iteration is calculated. They finally show that, depending on the algorithm complexity, the computation time of a truck appointment system for one iteration can be $2.6 \mathrm{~s}$ and that a trucking company needs, on average, 9.2 iterations to reach an acceptable result. These results show that TGSs addressing a wide mass of users need relatively high computational time.

Equally, truck guidance systems are studied also from the perspective of environmental emissions. Research conducted by Schulte et al. (2017) demonstrates that the appropriately coordinated truck schedules effectively reduce truck emissions and costs. Later, the research of Li et al. (2018) proposes a response strategy that can maintain high resilience ability of the system in neutralizing the impact of disruptions. Their evaluation is made based on two key performance indicators as follows: total waiting time of ontime trucks and total idling emissions of all trucks. They show that the appointments of trucks influence the yard-crane moving distance and that a resilient appoint systems for trucks reduce the operating cost for yard-cranes.

The literature review points out that there is a need for tools to optimize road haulage operations as the present ones serve local company-specific issues. Moreover, conditioned by low profit margins and being active in a high competitive market, companies offering road transport services depend on other stakeholders to set steps towards implementing ICT solutions (like a TGS) that increase transparency of operations. In addition, the above literature overview shows that academia addressed the impact of TGS from multiple perspectives (e.g. theoretical modelling, environmental 
savings, individual advantages for stakeholder etc.). In this context, there is a research gap that arises with regard to what are the necessary implementation steps to deploy a TGS. This issue is addressed further in detail by this study, and the next section presents the approach taken to determine the steps for successful TGS introduction.

\section{Research approach}

To achieve the objectives of this research, an in-depth desk research, a market analysis and a strategy analysis were conducted. Starting from the results of these analyses, several implementation strategies are defined and an analysis is later developed.

\section{Desk research}

The desk research was initiated to seek insights with regard to the contemporary and future technologies, and information systems that are developed for the trucking industry. This overview covers sources from scientific journals with regard to state-of-the-art technologies and optimization algorithms, real-time optimization methods in logistics, but also public implementation results of European projects and their proof-ofconcepts. Particular algorithms that were studied include optimal real-time routing as defined by Bast et al. (2016) and their real-life implementations as used also by Delling and Werneck (2015). A parallel desk research focused on identifying the type of costs and benefits that collaborative ICT solutions generally bring to port communities and their stakeholders. Finally, the desk research also identified truck-related ICT solutions at other ports pointing their scope, implementation issues and success factors.

\section{Market and strategy analysis}

A market analysis to disclose the state of ICT solutions developed and used by supply chain stakeholders was initiated. This analysis was conducted by carrying out semistructured interviews. In total, 30 companies were interviewed in the period June-October 2017. As shown in Fig. 2, the interview sample consisted of ten road transport operators, five shippers, four terminal operators, four IT solutions developers for trucking industry, two forwarders, two shipping agents, two ICT solutions developers, and one mobile operator. The length of interviews depended on the role and interest of the organization in the implementation of a TGS and varied between $45 \mathrm{~min}$ and two hours.

The semi-structured interviews were held with both chief executive officer (CEO) and ICT operational managers (if available) to identify a combination of technical and strategic elements embedded in contemporary working practices. The presence of the chief financial officer (CFO) and chief technology officer (CTO) was requested as well at the interviews, however when they were not available, their views were represented through the CEOs' statements. Appendix 1 presents the key questions guiding the interviews. This approach verifies whether a technological gap exists regarding the working practices of different MarSC stakeholders that have their activity linked with the port of Antwerp. The outcomes of this investigation are further used to define the further functionalities and architectural design of a TGS to avoid introducing potential discrepancies. 


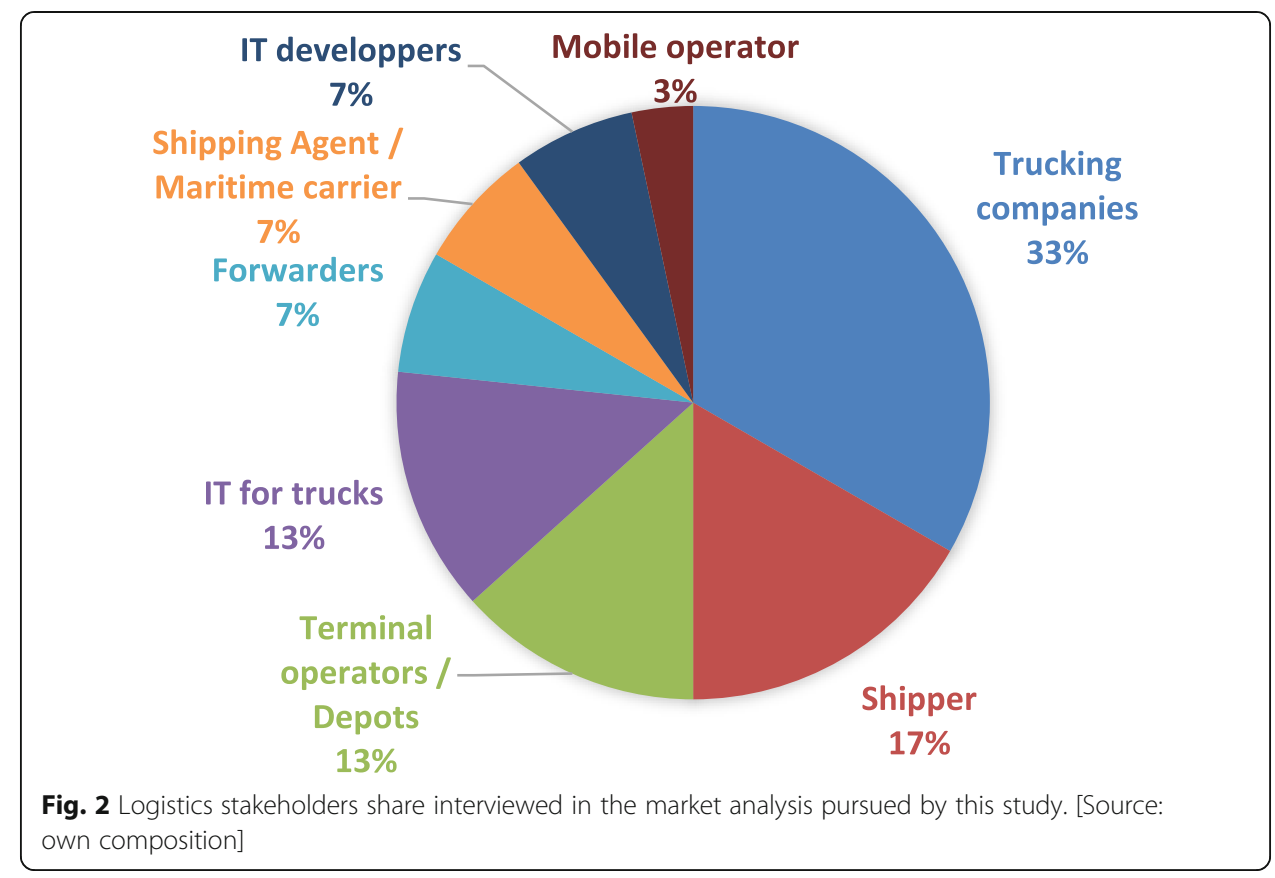

\section{Turning findings into implementation steps}

The results of the desk research, and the market and strategy analysis point out which consecutive TGS versions are to be developed. These TGS versions are considered as further implementation path and later analysed. At the interest of the port administration, the costs and benefits of a TGS are also pointed out. To do so, a comprehensive up-to-date framework, developed by Carlan et al. (2016), is applied for each version. This framework was developed after an in-depth literature review and, through its design, is applicable to ICT innovation that serves stakeholder communities in the MarSC and ports. Hence, the cost and benefit elements contained in this framework are thus relevant as well in a TGS case to be implemented at a seaport. As seen in Appendix 2, this framework consists of two parts. The first part provides a complete list of costs that are incurred by both the systems' operators and its users. Therefore, the stakeholders that incur the costs of such a system are pointed out. The second part puts forward the list of benefits that are generated by an ICT innovation. This list is divided in two sub-categories. While the first one points out the benefits gained from adhering to a digital solution, the second addresses the benefits of joining a communitybased system. ICT innovation benefits are identified from each participating stakeholders' standpoint.

\section{Analysis of implementation strategies}

Lastly, a number of implementation strategies are analysed. These strategies offer in-depth insights with regard to the involvement and potential strategies followed by the other stakeholders in implementing and using a TGS.

The results of the desk research and market and strategy analysis are presented in section 4. Section 5 takes lessons for implementation steps and strategies. 


\section{Findings of the desk research, and market and strategy analysis}

Supply chain operations are complex and require the active involvement of all the port stakeholders. This section gives an overview of the communication needs of port stakeholders.

\section{Contemporary road transport-related data communication needs}

Supply chain fragmentation due to lack of data still remains the main issue of contemporary transport operations (Kache and Seuring 2017). Ports' competitive strength depends mostly on the infrastructure they offer but also on the services around it. Traditionally, seaports are regarded as gateways for transferring cargo and passengers between vessels and shore. Ports represent the link in the supply chain where most supply chain stakeholders interact. Previous research (e.g., Coppens et al. 2007; Meersman et al. 2010) has focused on the relations of the supply chain stakeholders and analysed their influential roles in the operational decision making process. Yet, there are still integration issues that need to be settled between supply chain stakeholders, as Wiegmans et al. (2018) also points out. These issues are investigated through this research by addressing questions to industry representatives about the ICT tools and data they use in daily operations. In addition, questions on whether and which issues they do generate are also asked. These elements are retrieved through the questions addressed in sections 2 and 3, respectively, as presented in the interview guide added in Appendix 1. The interviews carried out with supply chain stakeholders that have their activity linked to road transport operations at the port of Antwerp pointed out the following issues. Firstly, road transport operators claim unreliable data with regard to driving times (also on alternative routes) and delays at terminals. Secondly, terminal operators, shippers or consignees point out the non-uniform truck arrivals and the lack of an ICT tool that centralize this information. Lastly, the forwarders claim the data fragmentation, information spread with regard to operations status and lack of possibility to offer reliable delivery-time estimation services.

This research at the port of Antwerp shows that SC stakeholders have developed own solutions to tackle some road transport-related operational issues. Contrary to expectations, although a lot of information is already available in a digital format, interviewees have pointed out that most of the data reading, processing and/or bundling is done manually. Moreover, supply chain stakeholders often work with extra time reserves when planning operative moves. Although no significant technological gap with regard to used technologies has been found, the presence of the human factor as data integrator is a common working practice. This practice is signalled as counterproductive and thus costly. From this overview, it is clear that new, integrative solutions and new agreements between the supply chain actors are necessary.

\section{Information sources, functionalities and architecture of a TGS}

A TGS cannot exist without the various data sources from different stakeholders in the transport chain. Reliable data sources are essential for feeding the system with the necessary information. In this section, an overview is given of all possible data sources that were identified during the desk research and interviews with stakeholders. Next to the data sources, the functionalities and the architecture of a state-of-the art TGS are 
put forward. Building insight in the future TGS was difficult and was done in close cooperation with the stakeholders involved, who often had different desires and sometimes even directly conflicting requirements. The design methodologies proposed initially by Fred and Brooks (1975) and later further developed by Tanenbaum and Wetherall (1996) or by Tanenbaum and Van Steen (2007) were followed, allowing for iterative refinement and adaptation. The current research acknowledges that the solution-space to the design problem actually forms a Pareto-front, and that multiple approaches, equally valid but with focus on different optimality, are possible and even desirable. This research aimed thus foremost at a valid design that flexibly fulfils most requirements from the stakeholders. Adaptability (i.e. being future proof with regard to technological advances and changing requirements) was an additional prime focus of attention.

\section{Information sources}

This sub-section details the key information necessary to a TGS. Table 1 presents a non-exhaustive list of information sources categorised by type.

As put forward in Table 1, key information necessary for the functioning of a TGS is scattered around. Information with regard to truck positioning and status provided from the on-board units is accessible through truck manufactures or on-board ICT providers. Specialized routing information is available through truck navigation providers and traffic information and decisions are released by road infrastructure managers and road authorities. Supply chain stakeholders, such as shippers, carriers, terminal operators or forwarders have in-house systems that contain information with regard to cargo, planning and estimated timing of operations. Collecting information from these sources is key in a fully automated TGS.

\section{Functionalities}

This sub-section explores the technical functionalities of a TGS.

From a technological point of view, an advanced future-proof TGS should consist of several built-in functionalities in order to offer the necessary features towards the enduser of the system.

The trucking sector emphasizes the need for real-time information with regard to road infrastructure status such as: status of bridges, lock passages, road works, parking availability; but also data to indicate driving times, waiting or transit durations at terminals. Table 2 gives an overview of technological features that are highly relevant for a TGS. Later in this study, a roadmap is presented on how these functionalities are added in a flexible and modular way, depending on priorities and feasibility in terms of openness of the stakeholders. Equally, the stakeholders that would incur the costs of developing and operating such as system, as well as the stakeholders that enjoy the benefits, are also identified.

Each of the presented functionalities enables further opportunities. The data collection and processing help ICT developers to further build algorithms as desired by port users (road transport operators, terminal operators, forwarders or carriers etc.). The visualisation layer and connection to the planners' back-end increase the accuracy of manual dispatching operations. By integrating the pre-booking system of terminal 
Table 1 Key information sources for a TGS [Source: own composition based on interviews results]

\begin{tabular}{ll}
\hline Key information & Source \\
\hline Truck information & ICT on-board providers offer ICT solutions for fleet management to \\
the transport industry, including backend software and on-board \\
units in trucks to locate and monitor in real time the status of the \\
truck fleet. Based on interviews with these solutions providers, they \\
show a clear interest in sharing at a certain cost their data to \\
interested parties. Within this regard, a TGS that utilizes this kind of \\
data is, from a technological and economic point of view, definitely \\
feasible. Some examples of data the providers can share include: \\
- GPS data with the position of the vehicles \\
- Driving and resting times of the drivers \\
- Speed \\
- Current activity
\end{tabular}

Mapping/navigation software and traffic information

Traffic management systems and road authorities

Shippers/ maritime carriers/ agents/ forwarders/ consignees systems

Terminal/ port/depot data/ (pre-gate) parking lots
Many navigation software applications already exist and are used by millions of drivers worldwide. Some examples are: Tom-Tom, Waze, Google Maps, Flitsmeister, Garmin, etc.. Applications generate crowdsourced data that is sent to specific backend systems. This data can then be fused with other traffic information sources, such as floating-car data, road sensors or tolling booths. All this information is then fed into the algorithms that determine optimal routes and provide traffic information to the end user via userfriendly interfaces.

For the traffic management, dynamic signalisation is deployed: lane signalisation above each lane and large text signs above and along the highways. The traffic measurements and steering of this signalisation is internally processed in different databases that are openly accessible.

Information from the shippers/forwarders could also be used by the TGS to have a better overview of planned transports. Information with regard to shipping orders can be predefined in central platforms so that shippers can reduce their cost by bundling their regular transportation needs with other shippers. In general, shippers, maritime carriers, agents, forwarders and consignees have their own information and thus are valuable sources of information in a supply chain. For example, real-time updates with regard to the expected delivery timing could be used by the TGS to optimize routing and planning.

Trucking companies delivering/picking-up goods to/from the port of Antwerp lack an integrating platform to announce and book their visit at each terminal. In this regard, there is a range of working practices from first-come-first-served to an hourly-based time slot booking system. Due to lack of coordination, it is very diffi cult to plan cross-terminal follow-up tasks.

An integration via a single sign-on platform between the TGS and the terminal operating systems would be very beneficial within this respect.

Data from terminals, ports or (empty) depots is beneficial for the

TGS, e.g.:

- Terminal slot data

- Queuing time at terminals

- Container availability

- Location of quay numbers

- Opening hours

Source: own composition from desk research and interviews

operators, one would reach a single sign-on planning platform with direct slot booking. Integration with infrastructure management systems provides a centralised traffic and parking management system. The link with SC stakeholders will enable booking and retrieval of shipping data. By developing and integrating the previous functionalities, a TGS would provide an integrated communication tool that would incorporate a dynamic traffic management system. 
Table 2 TGS functionalities [Source: own composition based on interviews results]

\begin{tabular}{ll}
\hline Functionality & Description \\
\hline Data gathering & Collecting the GPS location data/travelling times from the trucks (directly \\
& from a Truck Guidance (TG) app or indirectly via on-board computers) \\
& Collecting data from the infrastructure management authorities, navigation \\
& system providers and traffic information providers about road conditions, \\
& traffic jams or other incidents. \\
& Collecting data from terminals about available slots, container availability, \\
& quay numbers or opening hours. \\
& Collecting data from port, parking lots, gates, locks, bridges etc. about \\
& their status (e.g., queuing time, available space, bridge condition or \\
& opening hours). \\
& Analysing the traffic situation based on the collected data from different \\
& sources. \\
& Handling the availability of slots, e.g., late arrival, new slots proposal. \\
& Optimize pre-gate parking by indicating available spaces \\
(via sensors and/or parking entry/exit data. \\
Presenting in a user-friendly way the information towards the end-users \\
of the system (truck driver, planner, terminal operator, port operator, \\
forwarder or dispatcher), supporting different types of transport companies, \\
with very heterogeneous ICT capabilities. \\
Forwarding trucks in an optimal way to the terminal/loading area taking \\
into account available information (time slot, road conditions, etc.): via truck \\
information. \\
and recommendation \\
Integrating with the transport planner Traffic Management System to \\
optimize planning operations. \\
Integrating with terminal booking systems. \\
Integrating with parking lot booking system. \\
Integrating with other stakeholder systems. \\
Data Integration
\end{tabular}

Source: own composition from desk research and interviews

\section{Architecture}

The information provided by a TGS is the result of telematics services, combining both telecommunication and information technology. Figure 3 puts forward the architecture of a proposed TGS. Data gathering with regard to assets (e.g. containers, trucks, trailers) is essential. Moreover, additional information about the roads outside the port (e.g., current and expected traffic conditions) should be also gathered. Information about the scale and utilization of available trucking capacities will optimize the truck journeys, terminals' capacity or adjacent services usage (e.g. cleaning, servicing, parking etc.). It is important to allow users to select the data-sources they want to use, and neglect the others, in order to avoid a data-deluge. The modular design of the presented TGS architecture offers this kind of flexibility, preventing its overloading.

Based on the communication links that are described by Böse (2011), the architecture of an advanced TGS involves different stakeholders having their main activity in the same geographical area. Considering the information sources, the functionalities and the architecture needed, a TGS consists of three main building blocks as described also by Tanenbaum and Wetherall (1996), Tanenbaum and Van Steen (2007) or later by Böse (2011):

- TGS Backend: is responsible for gathering and storage of data from the different stakeholders and processing this data based on intelligent algorithms for optimized 


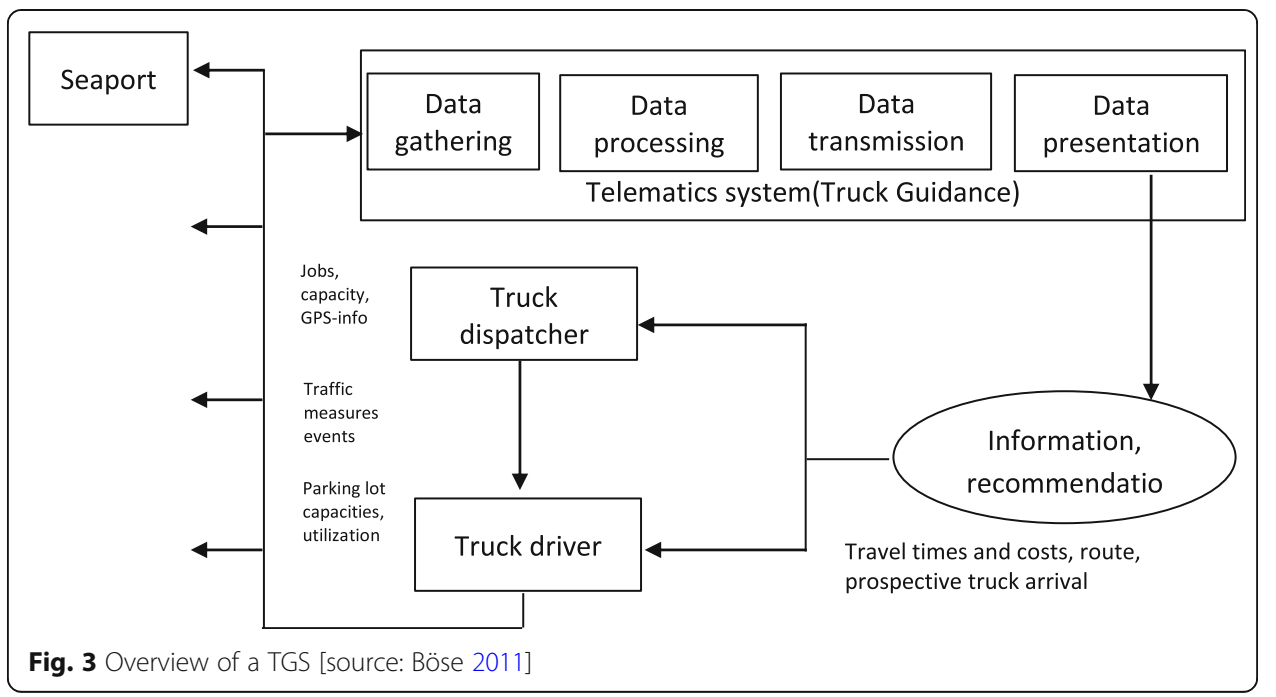

and intelligent routing calculation. The TGS backend should serve this information and recommendations to the remote end users in a user-friendly way. Privacy and confidentiality of the data handling is extremely important.

- TG Information System (towards its end users). To the end user, the TG Information System should present in a user-friendly way the information from the TGS backend, including traffic conditions, terminal data (e.g., slots), parking information, etc. This data can be presented via a web interface, an application on a smartphone/table or via the OBU.

- Interfaces between the TGS and the third-party systems. In order to exchange data between the different stakeholders and the TGS backend, either existing interfaces should be exploited or new interfaces need to be defined and implemented.

Beside the three main building blocks, a TGS must foresee the connection, through secure encrypted links, with the interested logistics stakeholders and to the tools of their operating personnel. For example, travel times must reach the web application used by dispatchers in the trucking companies or the mobile devices of the drivers. On the other side, an information link must be ensured also with the Terminal Operating System of the terminal operators, and the information panels used inside the terminals. Moreover, a TGS is seen as a further module offered through the logistics functionality of a PCS.

After having processed the outcome from the desk research, and market and strategy analysis, section 5 presents the main outcomes with respect to setting up a TGS.

\section{Proposal for developing a TGS}

Bringing the findings from section 4 together, it appears that the TGS functionalities are to be built following three intermediary solutions. Key statements are collected with regard to potential technologies, costs and benefits elements, other stakeholders or barriers (disadvantages) that are linked to the implementation of a TGS. These statements are collected by addressing questions as presented in section 4 of the interview guide (presented in Appendix 1) and processed. By doing so, intermediary solutions were 
identified during interviews with IT experts and validated by representatives of MarSC stakeholders. The sections below discuss the distribution of the costs and benefits of each intermediary solution. Further on, three implementation strategies are also analysed. The answers received with regard to the roles are shown that each logistics stakeholder might take in the potential development phases of a TGS. This input is gained by addressing the questions present in section 5 of the interview guide (shown in Appendix 1) to representatives of MarSC stakeholders.

\section{Intermediary solutions, costs incurred and stakeholders' benefits}

The adoption of each functionality and integration of each port stakeholder need from a TGS perspective follows a step-wise approach. The interviews with the stakeholders have revealed their potential involvement in implementing each intermediary version.

Having in mind the achievement of a fully dynamic TGS, before implementing this solution, two intermediary versions are foreseen to be operational. The initial version condition the implementation of the later ones. In this context, the final version is seen as a follow-up of the previous. Firstly, a basic TGS (bTGS) collects, processes and presents in a user-friendly way data necessary for planning operation at the port level. Secondly, an enhanced TGS (eTGS) ensures the connection to own systems of port stakeholders. Lastly, a fully automated TGS (faTGS) takes the condition of each stakeholder for operational purposes and enables them to build further cost-effective operational planning. This stepped approach, with these three specific parts, is chosen with the software interfaces in mind. Indeed, the layered approach abstracts away the specificities of the user-groups, allowing a more robust and modular software design. Regardless the fact that a TGS requires significant initial investments, it has high potential to increase the competitiveness of the community it serves. This potential is confirmed through the semi-structured interviews carried out. Through these interviews, MarSC stakeholders acknowledge the opportunities to take better planning decisions when data with regard to port infrastructure usage (road, parking, bridges, waiting locations, terminals' congestion, etc.) is provided through an integrated tool. This way, port users use information and can implement further own planning decision algorithms that incorporate cost-effective conditions. The following paragraphs put forward the intermediary solutions that a TGS can consist of and the interdependencies between them. Table 3 points out both the costs and the benefits incurred by port users that use a TGS. This outcome is derived from the answers received during the semi-structured interviews. Depending on the business model chosen, some users might incur costs. The potential presence of these costs in each TGS intermediary solution are marked within brackets in Table 3.

Legend: The following notation that identifies the costs and benefits presence in each version have been made: bTGS - for a basic TGS; e - for an enhanced TGS and faTGS - for a fully automated TGS.

\section{Basic TGS}

IT experts and SC stakeholders have pointed out during the interviews that data sources dispersion and heterogeneity are the two main problems in developing solutions for road transport. Yet, the cost and the capacities of integrating multiple data 


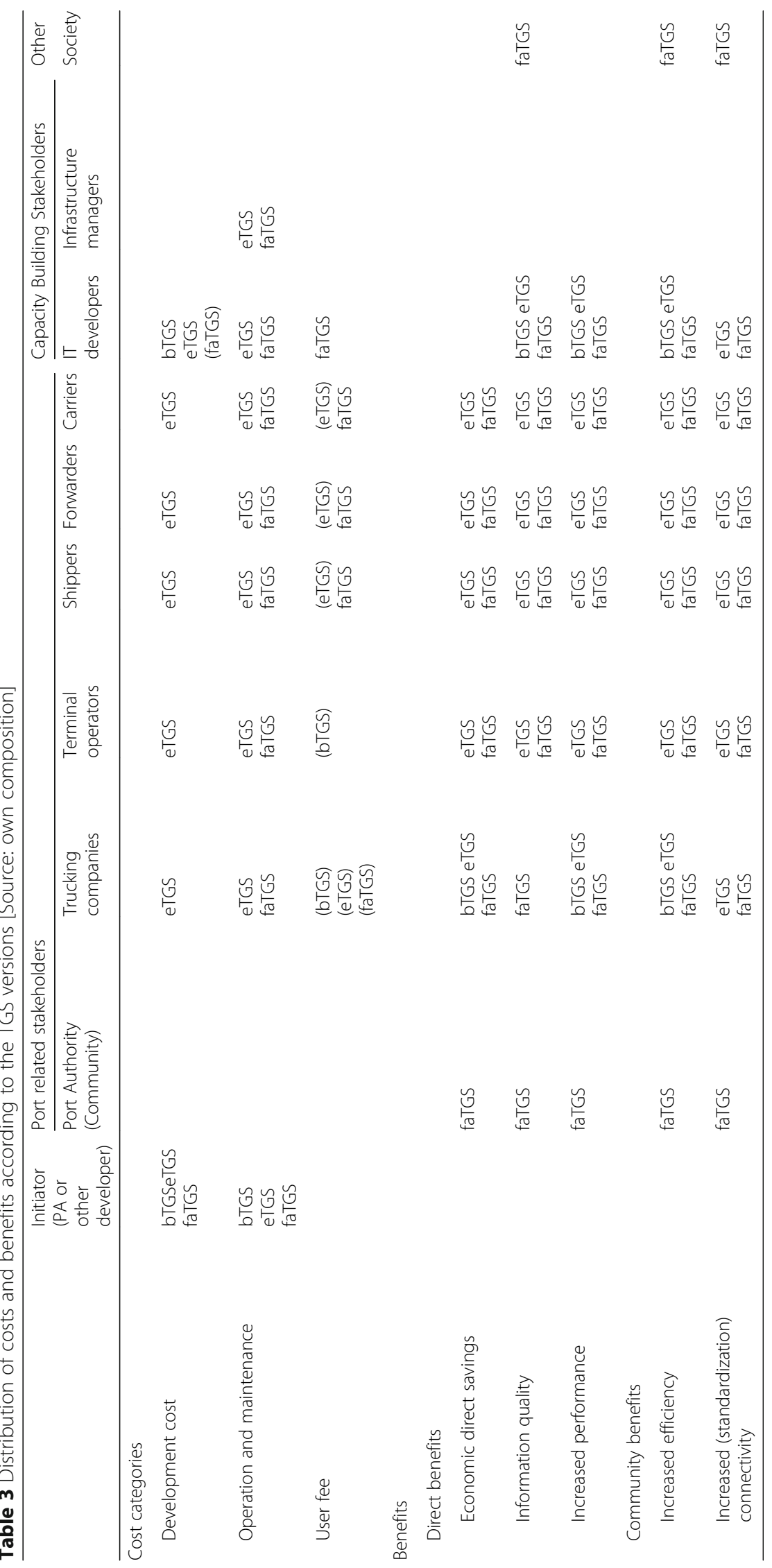


sources are barriers in achieving a functional TGS. Achieving this stage though would enable truck drivers and planners to gather information at once with regard to status of bridges, lock passages, road works, parking availability; but also data to indicate driving times, waiting or transit durations at terminals. Yet, road carriers face a major disadvantage from using robust technologies (set through on-board computers, stand-alone navigation systems etc.) that do not allow further integration with this type of data. Hence, data visualization and information delivery to users can be seen as sub-steps of this phase. The interviewed stakeholders indicated that data collection and bundling is a critical step in building any ICT solution.

In this step, the present study proposes the development of a truck guidance (TG) information system that includes the following building blocks (Böse 2011):

- A centralized TG provider backend (incl. The TG data, algorithms and web services)

The TG databases will retrieve their information from diverse sources like neighbouring cities, parking lots, bridges, locks (equipped with e.g., cameras, induction loops) and terminal operators.

- A local TG information system running at the trucking company (e.g. accessible by the planner/dispatcher) and running on-board the trucks (e.g. TG on-board info system accessible by the trucker, running on smartphone, tablet, $\mathrm{OBU})$. To retrieve up-to-date info in the truck, wireless Internet connectivity (3G/4G/Wi-Fi) at the truck location is a hard requirement.

The desk research has shown that digital information over each of these elements already exists, but the road transport operators have pointed out during interviews that there is little coordination (Wiegmans et al. 2018). Indeed, multiple data sources exist, presenting information for all the elements mentioned, but no coordinated hub providing the information in a standardized and uniform way is available. In effect, the data is scattered over multiple servers in wildly different formats and with varying strengths and quality. Moreover, digitalization and technology are no barriers (or disadvantages) anymore when more advanced technologies (that leverage on cloud solutions, remote processing etc.) are set in use. In this context, a neutral party could pursue this level of integration. After integrating these sources of information, public application programming interface (API)s could be opened for the use of a wide range of application developers.

To have a successful TGS, the cost of multiple data source integration is covered by the initiating party. In this regard, the interviewees have indicated that this initiating party has to be a neutral stakeholder that also would also need to ensure the operation and the follow-up of improvements introduced by these sources.

On the benefits side, from Table 3, it can be seen that the bundling of different information sources is mainly beneficial to the trucking industry. The trucking companies, by having direct access to real-time electronic information, would benefit from operational savings and increased performance. Also by bundling information in a onestop-shop type of system, it is expected that trucking companies will increase their efficiency. As a consequence, other third-party IT developers focused on services that are not directly linked to the trucking industry could benefit from higher information quality and a standardized data source. 


\section{Enhanced TGS}

This research shows that, besides the further integration of external data sources, building an enhanced TGS is a following step in achieving a fully automated TGS. That step concerns the connection to the planner's back end, integration with slot appointment systems at the terminals, integration with road infrastructure managements systems and linking other stakeholders' systems (such as shippers, maritime carriers, agents, forwarders, consignees). These actions, taken also in parallel, would enable the following results. Firstly, it creates a reliable planning based on centralized information by truck planners. Secondly, it contributes to increasing efficiency at the terminals by providing higher quality and reliable data with regard to road transport. Thirdly, it enables new management solutions for road infrastructure and parking capacity according to the demand. Finally, it updates actively the operational status of activities carried out in operations involving multiple stakeholders (e.g. providing shippers with details regarding whether their cargo has been unloaded from a vessel and what would be the expected time of pick-up by a road carrier.

Developing an enhanced TGS requires the collaboration of all the involved stakeholders with the developers of the current booking systems. Within this concept, road transporters, terminal operators, infrastructure managers and the other stakeholders (actors that do not operate the TGS), would be required to set up or link their operational planning software with the central platform. This step would enable the full range of benefits for road transport operators, terminal operators and infrastructure managers. Lastly, the other stakeholders enjoy benefits from getting access to improved reliable information.

Table 3 shows the costs and benefits put forward by a bTGS and indicates the additional brought by the implementation of an eTGS. After having road traffic data bundled, this version gives the opportunity to specialized IT developers to bring this information to the planner's back-end and thus offer extra value-added services. In this step, capacities and resources are required from both the user and the developers. Similar to the previous version, depending on the further functionalities, users might incur service costs. Getting real-time information from multiple sources directly in the dashboard would reduce the planner's effort in daily operations. This step would enable the full range of benefits for road transport operators.

As a further sub-step and depending on the availability of data, algorithms semiautomate the planning process based on real data and give suggestions to planners with regard to possible solutions. Equally, IT developers would enjoy benefits from having road traffic data on one platform to deliver value-added services. A data integration initiator (a neutral data integrating party) would be required to collaborate with terminal operators and use capacities (on the development and operational side) in common with the developers of current booking systems (IT companies, terminals etc.) at the terminals. Within this concept, terminal operators that do not operate a booking platform would be required to set up or link their operational planning software with the central platform. Road infrastructure management is a necessary element to increase the efficiency of a TGS. Data with regard to available capacity of road infrastructure, parking, scheduled road works, empty depots, bridges or tunnels is necessary for an effective TGS. The further centralized management of these elements would bring even more added-value services. 
The initiator of this version would incur the development costs together with the IT suppliers of existing electronic solutions. Furthermore, the same stakeholders, together with the infrastructure owners/managers, would support the operation and maintenance costs. These stakeholders would have to start a market analysis to measure the trucking companies' willingness to pay for electronic booking of parking locations, if feasible, and determine the feasibility of a user fee.

After having this version completed, further extension with value-added services to other supply chain stakeholders is enabled. In this solution, capacities and resources would be required from both a user perspective (such as shippers, forwarders or carriers) but also from the developers' side. Joint development efforts of supply chain stakeholders with own (inhouse) IT developers are necessary. Similar to initial version, depending on the further functionalities, users might incur costs when using value-added services. Getting real time information from multiple sources directly in their dashboard would reduce the employee's efforts. A short list of examples can be given, such as the calculation of transportation cost, real-time updates with regard to the expected delivery timing, etc. This version would enable the full range of benefits for shippers, forwarders and carriers. Equally, depending on the availability of data, algorithms are set in place to semi-automate the process of transport booking and retrieve real-time data. IT developers would enjoy benefits from having more data, enabling delivering more value-added services to their customers.

\section{Fully automated TGS}

A fully automated and dynamic TGS is a management system with real-time traffic and integrated transport for capacity management in and around ports. An additional layer representing the full integration with cooperative intelligent transport systems (C-ITS) technology is also considered. The goal of such a system is optimizing the planning and decision making based on new available C-ITS information coming from vehicles and infrastructure (Fig. 4).

This solution is developed to serve the mobility needs of the wide port community, improving the global cost-effectiveness of transport movements. In addition to the benefits of the enhanced TGS, Table 3 marks the effects of a fully-dynamic TGS on the port related stakeholders.

This overview puts forward the types of costs and benefits (additional to the two previous versions of a TGS) that each stakeholder involved in the truck guidance system would incur. The TGS development cost is incurred by the developing party (the port authority or a private stakeholder), while the operational and the maintenance efforts would be taken by the users, the logistics stakeholders. When fully operational, the fully dynamic slot booking system correlates the demands of each of the involved stakeholders. This system would adopt advanced decision algorithms to reach a global optimal solution for guiding the truck traffic in and in the vicinity of the port of Antwerp. This solution brings then benefits to the port users (the logistics stakeholders) and to the society as a whole.

\section{TGS strategies}

This sub-section puts forward three strategies that can be followed at a seaport for achieving an fully automated TGS. Under strategies is understood possible 


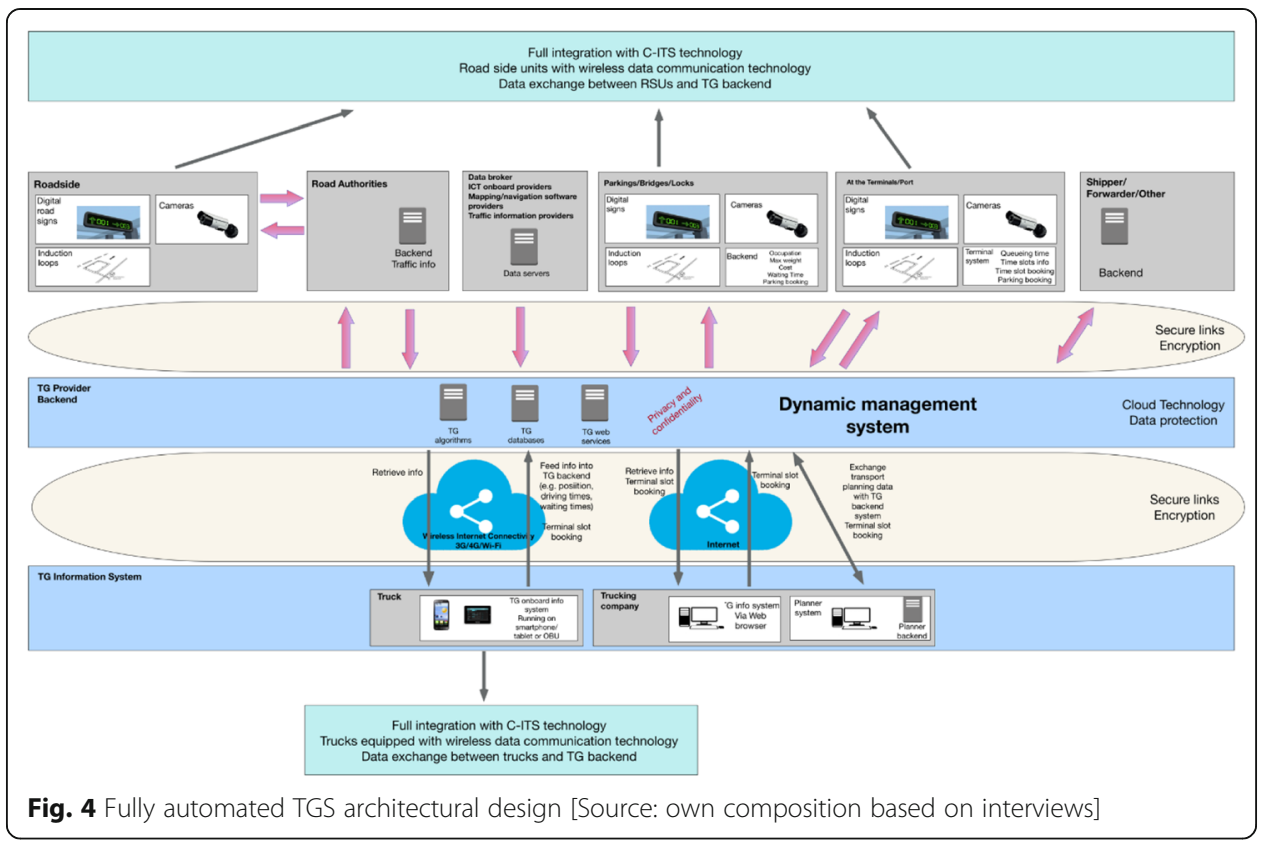

development tracks that have the same final goal. The proposed strategies discuss three possible approaches that the port administration can follow. The first strategy leaves the full implementation to the port administration, the second considers that private stakeholders would develop parts of the TGS and finally, and the third discusses the collaboration between the port authority and private stakeholders. These strategies are proposed to highlight on the one side the possible challenges and the interests of different stakeholders, but also to point out a possible collaboration formula towards the achievement of the TG implementation process. This section builds on the answers provided by the interviewees to the questions addressed in section 5 from the interview guide (presented in Appendix 1). Each strategy is represented in Table 4. This table puts forward the type of stakeholders that could be involved in each TG version and their role as follows: S - marks full specialization; NS - points out the need for further specialization; I - expresses stakeholder's interest; and the NoI - indicates no immediate interest. This outcome is derived from the input received during the semistructured interviews with the MarSC stakeholders.

\section{Strategy 1}

This strategy gives the port authority the entrepreneurial role of completely developing the truck guidance system. This development includes actions like: setting clear objectives to be reached, find and convince developing stakeholders to bring their expertise together, manage the development process, persuade the supply chain stakeholders, deal with the system's maintenance and constant up-date, and handle the return on investment strategy.

\section{Strategy 2}

This strategy considers the full contribution of private stakeholders in steps linked to the development of a TGS. The lack of coordination and the specialization of each 


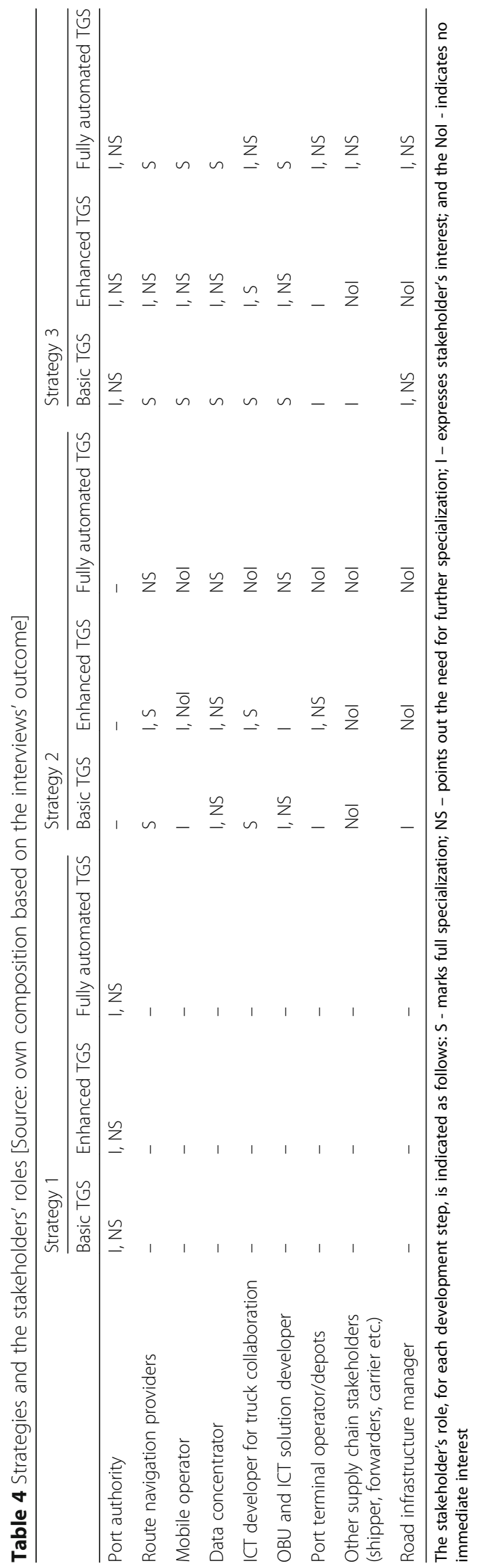


stakeholder are main challenges. In this strategy, each of the needed stakeholders for the implementation of a TGS would continue developing their expertise, but without the presence of a stakeholder ensuring the facilitator role, the majority of the stakeholders show no immediate interest in contributing to a fully automated TGS, as detailed in Table 4.

\section{Strategy 3}

This strategy suggests the implementation of a TGS while the port authority takes the enabler role. In this strategy, the port authority builds the developing trajectory and defines clear goals and acts as the facilitator to achieve these objectives. This way, already implemented solutions would be inventoried to further build on them. Also, the integration of a critical set of data to develop a comprehensive information system is needed (mapping of real-time traffic information, driving times on the road segments, waiting times and drive through time at the terminals). The specific development process of ICT systems linked to the different steps is delegated to specialized private stakeholders. This approach has the advantage that by expanding already in-place solutions an immediate market for early adopters will be reached. For the last version, further lobbying to interested parties is needed to indicate the port's strategy and to declare the demand for an enhanced truck guidance system.

\section{Conclusions and further recommendations}

This report presents an analysis of a TGS to be implemented at a seaport. The approach taken consists of both desk research and market and strategy analysis. The latter involves interviews with logistics stakeholders having their activity linked with the port of Antwerp. The desk research provides an overview of current operative practices in managing data sources related to truck movements and challenges faced by port users when working with this data. An overall TGS architecture is defined based on the desk research. Furthermore, different types of stakeholders from the ecosystem of the port of Antwerp gave their input and validated this architecture during semi-structured interviews. The outcomes of the desk research and interviews lead to the following key conclusions.

Firstly, this research identifies the main functionalities and architectural design of a fully automatic TGS. The implementation of this tool is foreseen to be carried out in three main steps. Each of these three steps delivers a version of the TGS. Regardless of the implementation version, a TGS consists of a fundamental data backend that gathers and stores data from the different stakeholders. This data backend provides a flexibleend where advanced algorithms for optimized routing calculation are plugged in. A further fundamental block is represented by an information system that visualizes, in a user-friendly way, the process-data from the backend. This information system is open for the use of each stakeholders. The last fundamental block is a comprehensive library of data-integration procedures, and interfaces between the TGS and other third-party systems. This library facilitates the easy implementation of data exchange functionalities by request between different stakeholders and the TGS's backend.

Secondly, a recommended roadmap towards the implementation of a fully automated TGS is detailed. This roadmap contains references to specialized data sources and 
identifies the SC stakeholders' operational needs. This roadmap points towards a stepwise approach. A first step is developing a basic system where only a few stakeholders are involved. Keeping in mind the architecture of an advanced TGS, where more and more stakeholders can become part of the complete system, the basis TGS needs to be flexible. This global view foresees a solution where end users can benefit from standardized digital data. A strong integration of real-time data streaming from each port user as part of a following enhanced TGS version. This version expands the benefits of the TGS to the wide mass of port users. A later fully automated TGS version that considers the full spectrum of data requirements of the port users is developed.

Thirdly, this research points out the conceptual costs and benefits incurred by MarSC stakeholders when using a TGS system. This study shows that a neutral stakeholder should cover the costs of multiple data source integration. The involvement of a neutral stakeholder is necessary to have an initial successful deployment of a TGS. This neutral stakeholder, by ensuring maintenance and processing services on data, can cover the initial investment. On the benefit side, trucking companies, by having direct access to real-time electronic information, would benefit from operational savings and increased performance. Other MarSC stakeholders (such as shippers, maritime carriers, agents, forwarders, consignees) receive as well benefits. These stakeholders can benefit from more data visibility with regard to road transport operations, set up reliable planning operations, better manage their infrastructure and develop added-value service for clients (track-and-trace services).

Fourthly, the strategy analysis suggests that a facilitator role taken by the port administration leads to the development and implementation of a fully automated TGS. This type of strategy would build on already implemented solutions, valuing the specialization of existing market solution developers.

The results of this research are relevant for both the academia and the industry. Clear theoretical aspects with regard to the fundamental necessities for building a TGS are put forward. Moreover, the industry benefits from a hands-on roadmap with reference to types of data sources and the MarSC stakeholders that provide this data. Moreover, the interest and (need for) specialization in taking part to different version of the TGS are identified.

This initial research into aspects of a TGS development at seaports opens several opportunities for further investigation as follows. This research did not explore the full span of development costs. In theory, development costs would be included in the cost recovery strategy, but since the concept is still to be developed, this issue remains uncertain (and may drag on for years). Similarly, issues such security, complexity of data integration and compatibility could influence the adoption and success of a TGS. These are not contained in the scope of the present analysis and are acknowledged as limitations. New research paths can explore the role of these elements in the adoption of a future TGS. Furthermore, this research proposes a comprehensive framework to quantify the benefits brought by a TGS. As attention on the environmental performance of road transport increases, in spite of improvements in that performance, it is appropriate for transport economists to give greater attention to the consequences of TGS in the environmental field as well. Another opportunity is to conduct a comparative study of already implemented systems across ports to point out the success and failure factors of TGSs. Equally, further research to investigate the cost effectiveness of different TGS governance structures is of interest. 


\section{Appendix 1}

\section{List of questions guiding the semi-structured interview}

1. Can you please provide us the following general information about company? (main activity; number of employees, annual turnover; business units and geographical scope, etc.)

2. Can you provide us information about the ICT tools used in daily operations at your company

2.1. Name the ICT tools used:

2.2. Who is the developer?

2.3. Info with regard to the acquisition/development? (ex. test product, simple acquisition contract, ...)

2.4. What are the existing functionalities of the technologies you use?

2.5. Are there any recurring costs to use the technology (e.g. data bundle subscription)?

2.6. Satisfaction? Are there any issues with the technologies you use?

3. Can you provide us information about the data used in daily operations at your company?

3.1. Which data you use in your daily operations?

3.2. Do you use specific data for each of the following operations?

3.3. Which data sources you use?

3.4. Do you have to pay for this data?

3.5. Under which format you receive this data?

3.6.Is it easily convertible to other formats?

4. Can you provide your perspective on the following aspects of a Truck guidance system

4.1. Which technologies should be connected with type of system? point from the existing technologies/IT systems.

4.2. What would be the quick wins and long term wins of such a system? Benefits: which benefits you expect to get from a TG system? How big do you thing those benefit would be? Would it be immediate? After 6 months? After 1 year? After 5 years?

4.3. What types of cost would this technology introduce? Acquisition, usage, need for investment in certain equipment, training etc.

4.4. Which actors should be involved in developing such a system? What role would they have and how strong should their involvement be?

4.5. What are the barriers and disadvantages in using each technology/IT system for a TG system? name disadvantages.

4.6. How could these barriers be overcome?

5. Can you provide your perspective the potential implementation of a TG system to be used by your company?

5.1. How would your company use and what is the role that your company can have in this solution?

5.2. Would your company invest in this solution?

5.3. Would your company pay to use this solution?

5.4. What are your company's drivers for the use of new technologies? 


\section{Appendix 2}

Table $\mathbf{5}$ Costs and benefits of ICT innovation in the maritime supply chain

\begin{tabular}{|c|c|}
\hline & Definition \\
\hline \multicolumn{2}{|l|}{ Cost categories } \\
\hline $\begin{array}{l}\text { Development and } \\
\text { implementation costs }\end{array}$ & $\begin{array}{l}\text { Development costs (including hardware/software acquisition/development } \\
\text { cost, staff cost, training etc.) }\end{array}$ \\
\hline Operation and maintenance & $\begin{array}{l}\text { Operating cost (staff cost, maintenance cost, storage and data management } \\
\text { costs) }\end{array}$ \\
\hline User costs & $\begin{array}{l}\text { Costs such as: connection costs, hardware software actuation development } \\
\text { cost, training cost, transition fees. }\end{array}$ \\
\hline \multicolumn{2}{|l|}{ Benefit categories } \\
\hline \multicolumn{2}{|l|}{ Direct benefits } \\
\hline Direct operational savings & Direct value of time and labour saved on operational activity \\
\hline Information quality & Value of time and labour for information up-take \\
\hline Increased performance & $\begin{array}{l}\text { Measure of activity increase (extra net income) due to more efficient } \\
\text { operations based on electronic data }\end{array}$ \\
\hline \multicolumn{2}{|l|}{ Community benefits } \\
\hline Increased efficiency & $\begin{array}{l}\text { Measure of activity increase due to community based information and/or } \\
\text { merged data }\end{array}$ \\
\hline $\begin{array}{l}\text { Increased (standardization) } \\
\text { connectivity }\end{array}$ & Measure of benefits from community added value services \\
\hline
\end{tabular}

Source: (Carlan et al. 2016)

\section{Abbreviations}

API : Application programing interface; bTGS : Basic truck guidance system; CEO : Chief executive officer; CFO : Chief financial officer; C-ITS : Cooperative intelligent transport system; CTO : Chief technology officer; eTGS : Enhanced truck guidance system; faTGS: Fully automated truck guidance system; ICT : Information communication technology; IoT : Internet of Things; IT: Information technology; OBU: On-board unit; SC : Supply chain; TG : Truck guidance; TGS: Truck guidance system

\section{Acknowledgements}

The authors would like to than the stakeholders representatives that accepted to participate in face-to-face interviews and added their contribution to the outcome of this paper. Special thanks are addressed also to the Port of Antwerp, for supporting and offering the opportunity to conduct this research.

\section{Authors' contributions}

Conceptualization: VC, DN, PA, BL, TV; Methodology: VC, DN, PA; Data curation: VC, DN, PA; Formal analysis: VC, DN, PA; Writing —original draft preparation: VC, DN, PA; Writing - review and editing: VC, DN, PA, BL, TV. All authors read and approved the final manuscript.

\section{Funding}

This research is carried with funding from the Port of Antwerp, Belgium at the University of Antwerp titled "Truck Guidance System - Scoping van inhoud en opstellen van een stappenplan om tot realisatie te komen", contract number OC2901. The funding body covered activities from design of the study to collection of data, analysis and interpretation of data.

\section{Availability of data and materials}

The data based on which findings and conclusions were made is collected by the authors of this paper though direct interviews with representatives of supply chain stakeholders. For confidentiality reasons this data is not made public, however it may at any moment be checked with the authors.

\section{Competing interests}

The authors declare that they have no competing interests.

\section{Author details}

${ }^{1}$ Department Transport \& Regional Economics, University of Antwerp, Prinsstraat 13, 2000 Antwerpen, Belgium. ${ }^{2}$ ImecIDLab - Universiteit Gent, Technologiepark-Zwijnaarde 15, 9052 Ghent, Belgium. 
Received: 30 May 2019 Accepted: 19 November 2019

\section{Published online: 05 December 2019}

\section{References}

Bast H, Delling D, Goldberg A, Müller-Hannemann M, Pajor T, Sanders P, .. Werneck RF (2016). Route planning in transportation networks. In: Algorithm engineering (pp. 19-80). Springer

Böse JW (2011) Handbook of terminal planning. Retrieved from //www.springer.com/gp/book/9781441984074

Cao M, Vonderembse MA, Zhang Q, Ragu-Nathan TS (2010) Supply chain collaboration: conceptualisation and instrument development. Int J Prod Res 48(22):6613-6635

Carlan V, Sys C, Vanelslander T (2016) How port community systems can contribute to port competitiveness: developing a cost-benefit framework. Res Transp Bus Manag. https://doi.org/10.1016/j.rtbm.2016.03.009

Castelein RB, Geerlings H, van Duin JHR (2019) Divergent effects of container port choice incentives on users' behavior. Transp Policy. https://doi.org/10.1016/j.tranpol.2019.04.010

Coppens F, Lagneaux F, Meersman H, Sellekaerts N, van de Voorde E, van Gastel G, .. Verhetsel A (2007) Economic impact of port activity: a disaggregate analysis-the case of Antwerp. Retrieved from https://papers.ssrn.com/sol3/papers. cfm?abstract_id $=1687569$

D’Este P, lammarino S, Savona M, von Tunzelmann N (2012) What hampers innovation? Revealed barriers versus deterring barriers. Res Policy 41(2):482-488

Delling D, Werneck RF (2015) Customizable point-of-interest queries in road networks. IEEE Trans Knowl Data Eng 27(3):686698

FOD Mobiliteit (2017) Editie 2017 | FOD Mobiliteit. Retrieved March 21, 2018, from https://mobilit.belgium.be/nl/mobiliteit/ woon_werkverkeer/editie_2017

Fred B, Brooks P (1975) The mythical man month. Proceedings of the international conference on reliable software, 193

Haralambides H (2017) Globalization, public sector reform, and the role of ports in international supply chains. Marit Econ Logistics 19(1):1-51. https://doi.org/10.1057/s41278-017-0068-6

Harris I, Wang Y, Wang H (2015) ICT in multimodal transport and technological trends: unleashing potential for the future. Int J Prod Econ 159:88-103. https://doi.org/10.1016/j.ijpe.2014.09.005

Hill A, Böse JW (2017) A decision support system for improved resource planning and truck routing at logistic nodes. Inf Technol Manag 18(3):241-251

Kache F, Seuring S (2017) Challenges and opportunities of digital information at the intersection of big data analytics and supply chain management. Int J Oper Prod Manag 37(1):10-36

Li N, Chen G, Govindan K, Jin Z (2018) Disruption management for truck appointment system at a container terminal: a green initiative. Transp Res Part D: Transp Environ 61:261-273. https://doi.org/10.1016/j.trd.2015.12.014

Meersman H, Van De Voorde E, Vanelslander T (2010) Port competition revisited. Rev Bus Econ Lit 55(2):210-233

Mohr D, Müller N, Krieg A, Gao P, Kaas H-W, Krieger A, Hensley R (2013) The road to 2020 and beyond. In: What's driving the global automotive industry? McKinsey \& Company Inc., New York

Panayides PM, Song D-W (2013) Maritime logistics as an emerging discipline. Marit Policy Manag 40(3):295-308

Phan M-H, Kim KH (2016) Collaborative truck scheduling and appointments for trucking companies and container terminals. Transp Res B Methodol 86:37-50. https://doi.org/10.1016/j.trb.2016.01.006

Rushton A, Croucher P, Baker P (2014) The handbook of logistics and distribution management: understanding the supply chain. Kogan Page Publishers, London

Schulte F, Lalla-Ruiz E, González-Ramírez RG, Voß S (2017) Reducing port-related empty truck emissions: a mathematical approach for truck appointments with collaboration. Transport Res E: Logistics Transport Rev 105:195-212. https://doi. org/10.1016/j.tre.2017.03.008

Song D-W, Panayides PM (2008) Global supply chain and port/terminal: integration and competitiveness. Marit Policy Manag 35(1):73-87

Tanenbaum AS, Van Steen M (2007) Distributed systems: principles and paradigms. Prentice-Hall, Upper Saddle River

Tanenbaum AS, Wetherall D (1996) Computer networks. Prentice Hall, Upper Saddle River

Wiegmans B, Menger I, Behdani B, van Arem B (2018) Communication between deep sea container terminals and hinterland stakeholders: information needs and the relevance of information exchange. Marit Econ Logistics 20(4):531-548. https:// doi.org/10.1057/s41278-017-0071-y

Woo S-H, Pettit SJ, Beresford AK (2013) An assessment of the integration of seaports into supply chains using a structural equation model. Supply Chain Manag Int J 18(3):235-252

Yanhong F, Xiaofa S (2013) Research on freight truck operation characteristics based on GPS data. Procedia Soc Behav Sci 96: 2320-2331. https://doi.org/10.1016/j.sbspro.2013.08.261

Zehendner E, Feillet D (2014) Benefits of a truck appointment system on the service quality of inland transport modes at a multimodal container terminal. Eur J Oper Res 235(2):461-469. https://doi.org/10.1016/j.ejor.2013.07.005

Zhang X, Zeng Q, Chen W (2013) Optimization model for truck appointment in container terminals. Procedia Soc Behav Sci 96:1938-1947. https://doi.org/10.1016/j.sbspro.2013.08.219

Zhao W, Goodchild AV (2010) The impact of truck arrival information on container terminal rehandling. Transport Res E: Logistics Transport Rev 46(3):327-343

\section{Publisher's Note}

Springer Nature remains neutral with regard to jurisdictional claims in published maps and institutional affiliations. 